\title{
Zwei Restitutionen an der WLB erfolgreich durchgeführt
}

Im Rahmen des Projekts „Suche nach NS-Raubgut in den Beständen der Württembergischen Landesbibliothek Stuttgart", das vom Deutschen Zentrum Kulturgutverluste und dem Ministerium für Wissenschaft, Forschung und Kunst des Landes Baden-Württemberg für die Dauer von drei Jahren gefördert wird, konnten erneut zwei Restitutionen durchgeführt werden.

\section{Restitution an die Loge „Johannes zum wiedererbauten Tempel“" Ludwigsburg}

tution von 99 Bänden aus dem Besitz der "Loge Johannes zum wiedererbauten Tempel" statt. Unter der Großloge "Zur Sonne» in Bayreuth

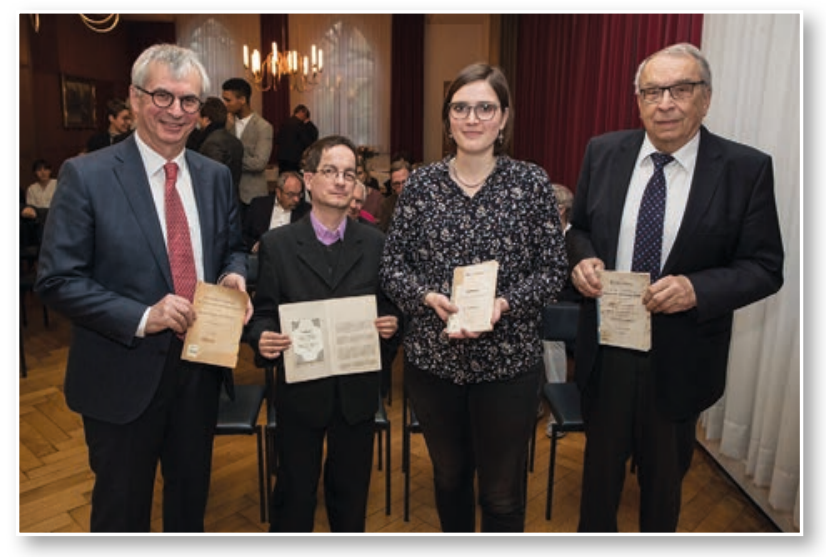

Abb. 1: Elefterios Vasiliadis (Meister vom Stuhl), Dr. Hans-Christian Pust, Maria Nüchter und Otto Thum bei der Übergabe der Bücher. Foto: Andreas Essig

wurde am 1. Juli 1855 die heutige Ludwigsburger Loge "Johannes zum wiedererbauten Tempel" gegründet. 1887 begannen die Arbeiten am Logenhaus in der Asperger Strasse 37. 1888 wurde das Logenhaus feierlich eingeweiht. Nach dem Machtantritt der Nationalsozialisten wurde die Loge am 20. April 1933 gewaltsam aufgelöst. 1935 ging das Logenhaus in den Besitz der Stadt Ludwigsburg über. Die SA bezog das »Haus der Humanität« bis 1945. Nach Kriegsende konnte am 14. Februar 1946 die Ludwigsburger Freimaurerloge ihre Arbeit wieder aufnehmen. In diesem Jahr wurde auch das Logenhaus an die Loge zurückgegeben. Insgesamt wurden bis jetzt 99 Bücher aus den

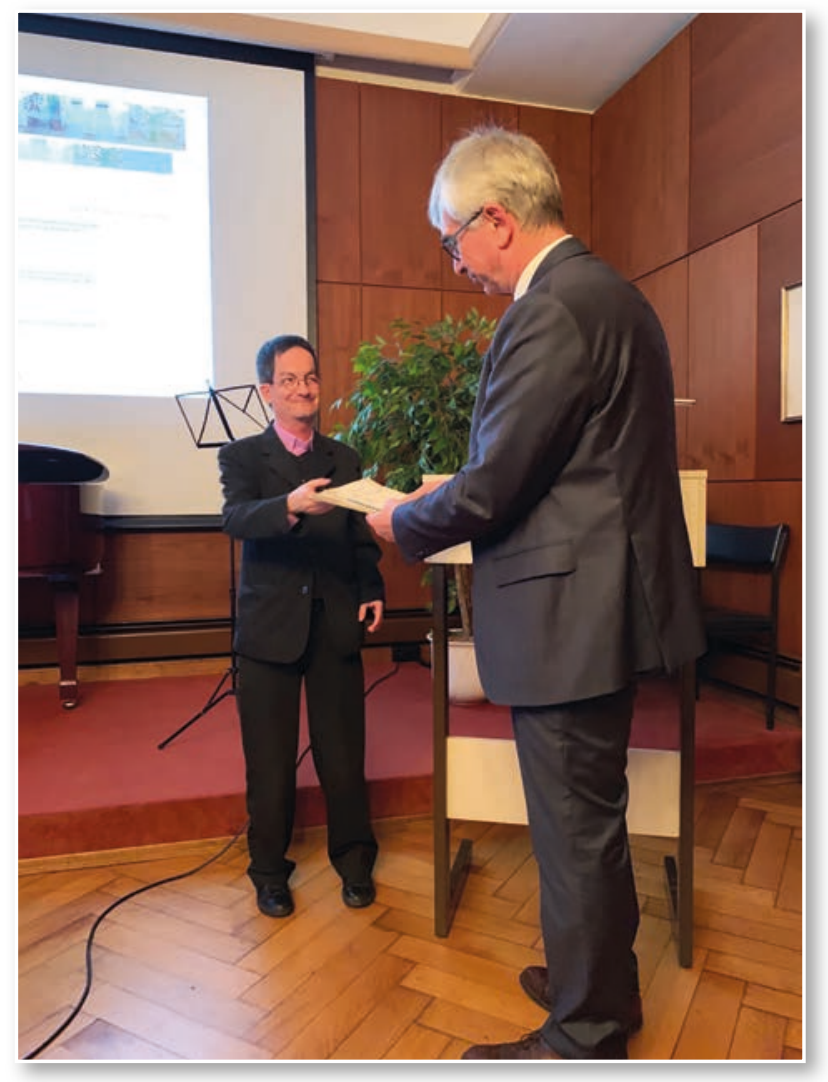

Abb. 2: Dr. Hans-Christian Pust bei der Übergabe der Bücher an Elefterios Vasiliadis (Meister vom Stuhl).

Beständen der Loge aus Ludwigsburg in der Württembergischen Landesbibliothek gefunden. Die Bücher kamen 1934 als „Geschenk" eines Mitglieds der Loge in die Bibliothek. Durch die Schenkung an die WLB versuchten die Logenmitglieder vermutlich, ihre Bibliothek vor einer Beschlagnahmung zu retten.

Die Bücher aus dem Besitz der Loge konnten bei einer kleinen Feierlichkeit im Haus der Loge restituiert werden. Herausragend sind drei Schriften, die aus der Anfangszeit der Loge stammen. Sie sind in kaum einer anderen Bibliothek in Deutschland vorhanden. Vor der Restitution wurden die Bände digitalisiert und sind nun in den Digitalen Sammlungen der WLB zugänglich. 


\section{Restitution an die Erben von Georg und Irma Baruch}

Am 10.09.2019 fand in Hamburg in der Galerie Morgenland die Restitution von 14 Bänden aus dem Besitz von Georg und Irma Baruch statt.

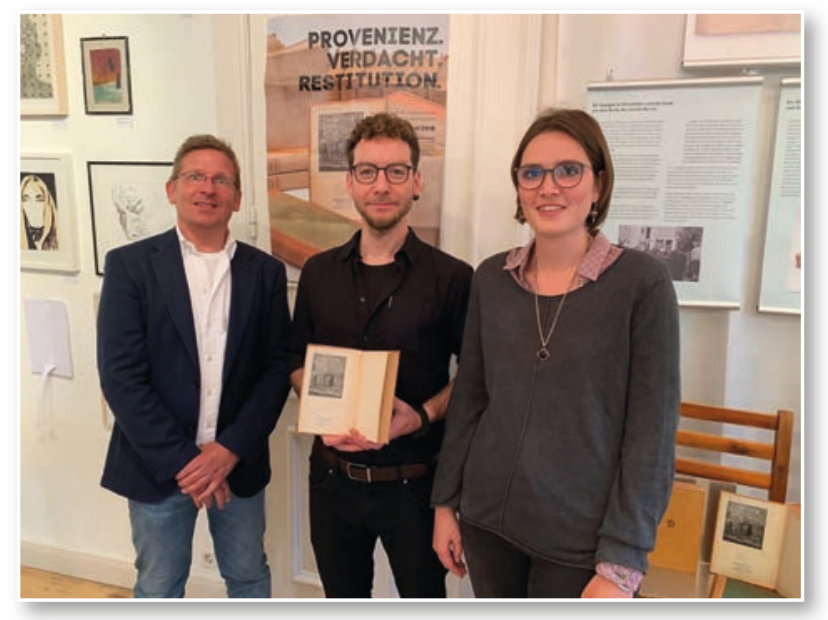

Abb. 3: Der Urenkel der Familie Baruch (Mitte) bei der Übergabe der Bücher gemeinsam mit dem Geschäftsführer der Geschichtswerkstatt Eimsbüttel/Galerie Morgenland Jörg Petersen (links) und Maria Nüchter (rechts).

Im bis jetzt untersuchten Bestand wurden 14 Bücher aus der Bibliothek des jüdischen Ehepaars Georg (1881-1941) und Irma Baruch (1887-1936) aus Hamburg gefunden. Jedes dieser Bücher ist mit dem Exlibris des Ehepaars versehen, das die Namen der Eheleute trägt und einen Knaben auf den Felsen von Helgoland zeigt, der zwei dicke

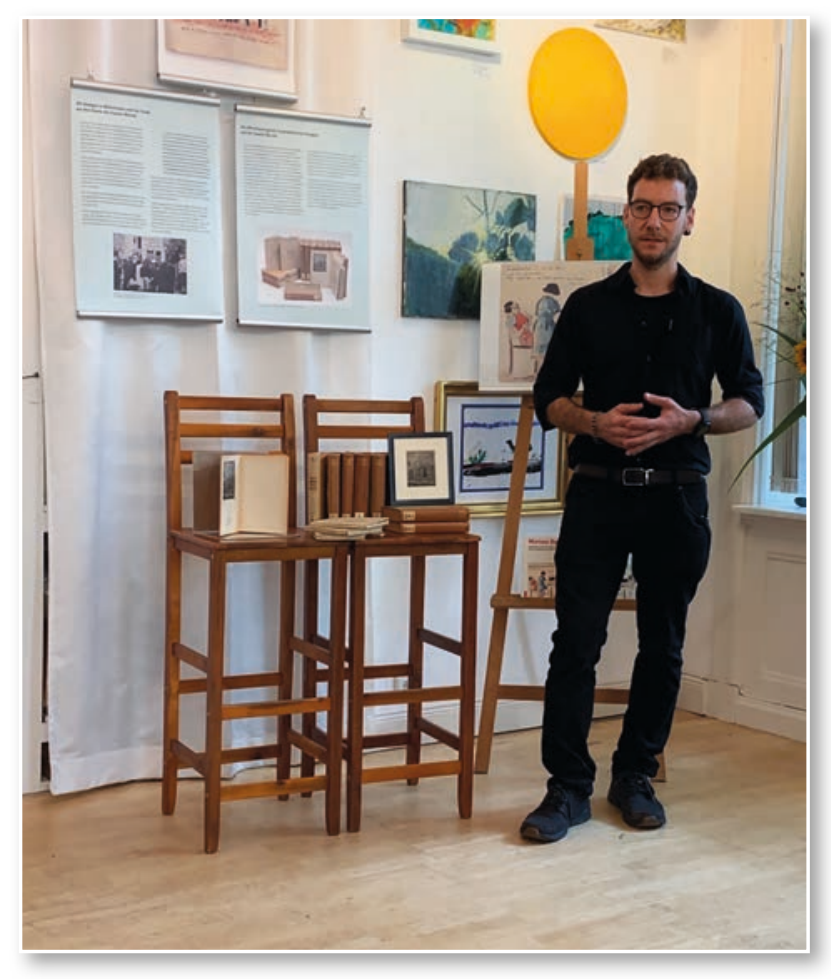

Abb. 4: Der Urenkel der Familie Baruch neben den Büchern.
Bücher unter den Arm geklemmt hat. Georg Baruch war ein Hamburger Kaufmann und wurde am 8. November 1941 mit seiner Tochter Marion nach Minsk deportiert. Sein Sohn wurde in Auschwitz ermordet, nur die zweite Tochter konnte nach Israel emigrieren.

Bei der Recherche nach dem Ehepaar Baruch wird deutlich, mit welch großem Nutzen die NSRaubgutforschung auf Ergebnisse der NS-OpferForschung zurückgreifen kann. Zahlreiche Erkenntnisse liefern insbesondere die in vielen deutschen Städten arbeitenden Stolperstein-Initiativen, die NS-Opfer recherchieren, ihre Lebensgeschichten erforschen und so genannte "Stolpersteine" vor den Gebäuden, in denen die Opfer zuletzt gelebt haben, verlegen. So gibt es in Hamburg auch Stolpersteine für Georg Baruch und seine beiden ermordeten Kinder. Die Geschichte der Familie ist auf der Website der Hamburger StolpersteinInitiative ausführlich dokumentiert. In sämtlichen in der WLB gefundenen Büchern mit dem Exlibris des Ehepaars Baruch fand sich ein weiterer Stempel des Stuttgarter Apothekers Paul Braun. Wann genau und unter welchen Umständen Paul Braun in den Besitz dieser Bücher gekommen ist, ist nicht bekannt.

Die Bücher wurden an einen Urenkel der Familie Baruch restitutiert, der heute wieder in Hamburg lebt.

Maria Nüchter / Hans-Christian Pust 